\title{
SÍNTESE DE SCAFFOLD POROSO DE AGAROSE E COLÁGENO PARA APLICAÇÕES EM ENGENHARIA DE TECIDOS
}

\author{
Rogério Macedo da Silva Júnior ${ }^{1}$, Marilia Alves de Lima ${ }^{1}$, Rodrigo Juan Martins Cardozo ${ }^{1}$, Talita Feliciano de Souza ${ }^{2}$, \\ Ricardo Yara*
}

\begin{abstract}
1'Laboratório de Biofísica Química, UFPE, ²Discente do curso de Engenharia Biomédica UFPE/CTG,
${ }^{3}$ Docente do curso de Engenharia Biomédica UFPE/CTG. *ricardo.yara@ufpe.br
\end{abstract}

\begin{abstract}
INTRODUÇÃO
A Engenharia de Tecidos é um campo multidisciplinar entre as á reas de ciência e engenharia de materiais, biofísica, bioquímica, ciências biomédicas e medicina que tem como objetivo desenvolver conhecimentos e técnicas para o reparo de funções e a reconstrução de órgãos e tecidos lesionados a partir da cultura e expansão in vitro de células sobre suportes sintéticos tridimensionais (scaffolds) de materiais biorreabsorvíveis (BARBANTI, et al., 2005; MA, 2008; AWAD, et al., 2004).

Doenças crônico-degenerativas são responsáveis por dois terços de todas as mortes no mundo. Essas patologias alteram o funcionamento do corpo humano desde células e tecidos, até sistemas inteiros, causando necrose, lesões graves e perda de funç ões. As intervenções terapêuticas atuais envolvem o uso de fá rmacos e em muitos casos cirurgias. Dentro desse contexto, a Engenharia de Tecidos abre perspectivas para a pesquisa e desenvolvimento de métodos eficazes no tratamento de diversas dessas patologias crônico-degenerativas (MCGEER, 2004; SANTOS,
\end{abstract} et al., 2004; WHO, 2014).

A adesão e proliferação de células em matrizes artificiais dependem dos métodos utilizados na produção desses materiais. Algumas características têm sido estudadas, como a biocompatibilidade dos suportes, a biodegradação controlada para que haja uma recuperação adequada do tecido, e o dimensionamento dos poros. Sendo esta última característica de importância relevante já que a porosidade interfere diretamente na adesão, desenvolvimento e morfologia das células, além de determinar o nível do fluxo de substâncias essenciais para o crescimento celular. Materiais porosos facilitam estes processos, além de proporcionarem uma melhor neovascularização da área do tecido que está sendo reparada (HUTMACHER, 2000; SITTINGER et al., 1995; BHAT et al. 2010; SANCHEZ-SALCEDO et al. 2008).

Os polímeros naturais obtidos por processos industriais escalonados como a agarose e o colágeno tem um menor custo associado a matéria-prima (YANG et al., 2004) diminuindo consequentemente o custo de produção de dispositivos e se apresenta como alternativas clínicas para o tratamento e regeneração de órgãos e tecidos. Ademais, utilização de polímeros de origem natural como a agarose e o colágeno na síntese de scaffolds tem demonstrado bons resultados devido à biocompatibilidade apresentada por esses materiais e suas características físico-químicas semelhantes às da ECM. Estas características podem garantir o estabelecimento celular e o consequente desenvolvimento de uma nova matriz gerada pela produção de proteoglicanos e colágeno pelas células recém-estabelecidas.
O uso de agarose, um polissacarídeo derivado de algas marinhas, já é bastante difundido no campo biomédico, tendo aplicações també $\mathrm{m}$ na liberação controlada de fármacos. Entre suas propriedades estão as características mecânicas desejadas. 0 colágeno processado apresenta propriedades semelhantes às do polímero análogos ao encontrado no organismo humano, e tem um tem sido frequentemente utilizado produção de scaffolds. (MALAFAYA, et al., 2007; CEN et al., 2008; DANG, LEONG, 2006; SAKAl et al., 2006).

Logo, o presente estudo tem como objetivo o desenvolvimento de scaffolds porosos que favoreçam a adesão e o crescimento celular baseados em agarose e colágeno.

\section{MATERIAIS E MÉTODOS}

Os experimentos foram realizados no Laboratório de Biofísica Quí mica do Departamento de Biofísica e Radiobiologia (LBQ) como parte das atividades obrigatórias da disciplina de Engenharia de Tecidos (BIO 0008) do curso de Engenharia Biomédica no período 2017.2.

Foram realizados dois procedimentos, sendo o primeiro a síntese de scaffold poroso pelo procedimento descrito por Bhat et al. (2012) modificado. Foram utilizados como materiais agarose $(3 \%$ $\mathrm{w} / \mathrm{v})$, colágeno $(1 \%)$, glutaraldeído $(0,2 \%)$. Neste procedimento foram diluídos em água destilada a agarose e o colágeno $\left(40^{\circ} \mathrm{C}-70^{\circ}\right.$ C), após a diluição a solução foi levada ao vórtex. Em seguida foi adicionada a solução de $0,5 \mathrm{~mL}$ de glutaraldeído a $0,2 \%$ de $25 \%$ da solução de estoque. A solução foi agitada num béquer de $3 \mathrm{~L}$ até formar uma espuma densa. Foram transferidos $5 \mathrm{~mL}$ da espuma de agarose, colágeno e glutaraldeído para um tubo Falcon de $15 \mathrm{~mL} e$ incubados a $-12^{\circ} \mathrm{C}$ no freezer durante um período de $16 \mathrm{~h}$. Após as $16 \mathrm{~h}$, a solução foi retirada e enxaguada em água destilada durante a noite inteira utilizando a mesa agitadora para retirar o glutaraldeído que não reagiu.

O segundo procedimento foi a síntese de scaffold poroso por erosão de sal onde foram utilizados agarose $(3 \% \mathrm{w} / \mathrm{v})$, colágeno $(1 \%)$ e $\mathrm{NaCl}(600 \mathrm{mg})$. Neste segundo experimento, foram diluídos em á gua destilada a agarose e o colágeno $\left(40^{\circ} \mathrm{C}-70^{\circ} \mathrm{C}\right)$, após a diluição a solução foi levada ao vórtex. Foram transferidos $5 \mathrm{~mL}$ da solução para uma forma de silicone de $7 \mathrm{~mL}$. Em seguida adicionou-se 600 $\mathrm{mg}$ de sal. Também foi feita a confecção de uma peça de controle transferindo $5 \mathrm{~mL}$ da mesma solução para uma forma de silicone com o mesmo tamanho $(7 \mathrm{~mL})$, porém, sem adição de $\mathrm{NaCl}$. 0 material foi incubado em uma estufa $45^{\circ} \mathrm{C}$ para secagem. Por fim, houve a lavagem com água destilada para erosão do sal por um perí odo de $4 \mathrm{~h}$. 
Para o segundo procedimento após a lixiviação do sal, foram feitos cortes com uma lâmina de aço inoxidável para visualização do material. O material foi corado numa solução de Cristal Violeta (Hexamethylenepararosaniline chloride), sendo lavado novamente para retirada do excesso do corante e visualizado em microscópio ó ptico em objetiva de $40 \mathrm{X}$.

\section{RESULTADOS E DISCUSSÃO}

Dois métodos diferentes foram testados para a síntese dos scaffolds, no primeiro método, síntese de scaffold poroso utilizando o procedimento de Bhat et al. (2012) modificado, houve formação de espuma que em teoria induziria a formação de poros, porém foi observada que a espuma não estava uniformemente distribuída no material (figura $1 \mathrm{~A}$ ).

Após a produção da espuma o material foi congelado e em seguida descongelado em temperatura ambiente. Foi observado que após este procedimento a espuma se desfez e o material colapsou (figura 1B), o que tornou suas características insatisfatórias para utilização como scaffold.
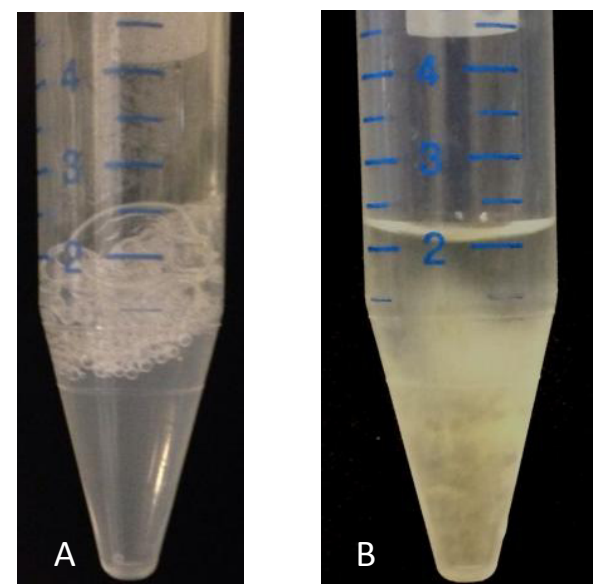

Figura 1. Scaffold sintetizado pela técnica de síntese descrita por Bhat et al. (2012 modificada) (A) Antes do congelamento é possivel observar poros formados no material pela espuma distribuindo-se pela superfície do material. (B) após descongelamento em temperatura ambiente, já não é mais possível observar poros no material. Houve a degradação da espuma no decorrer do descongelamento e a consequente degradação dos poros antes formados.

No segundo método, síntese de scaffold poroso por erosão de sal, foi verificado que após a lavagem com água destilada o material apresentou a formação de poros uniformes (figura 2).

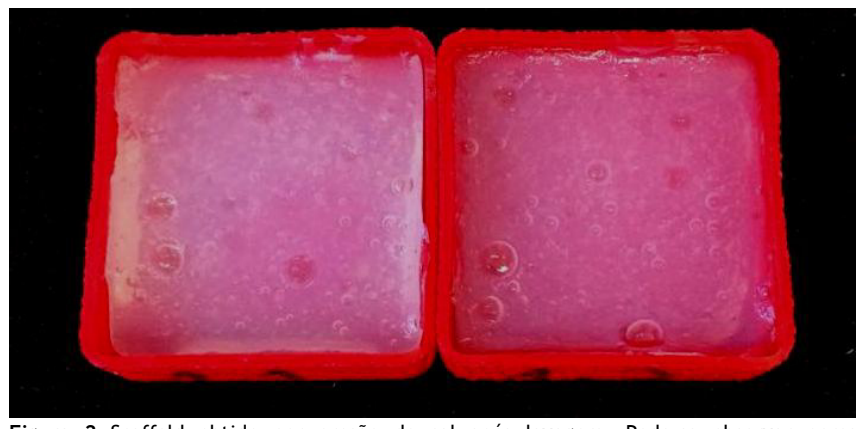

Figura 2 Scaffold obtido por erosão de sal após lavagem. Pode-se observar poros macroscópicos na estrutura obtidas

O material produzido utilizando o método por erosão de sal, apresentou a formação de poros que se mantiveram estáveis mesmo após o período de secagem na estufa e lavagem, o que indica que há possibilidade de utilização deste material como scaffold.
Para o segundo procedimento após a retirada do sal, foram realizados cortes histológicos a mão utilizando lâminas de aço inoxidável seguido de coloração por Cristal Violeta. Observa-se que no material onde não houve a inclusão de sal a superfícies se apresentava uniforme (figura $3 \mathrm{~A}$ ). Enquanto o material sofre $\mathrm{O}$ processo de inclusão e posterior erosão a superfície torna-se irregular, podendo ser observados diversos poros quando o material é examinado no aumento de 40x (figura 3B).

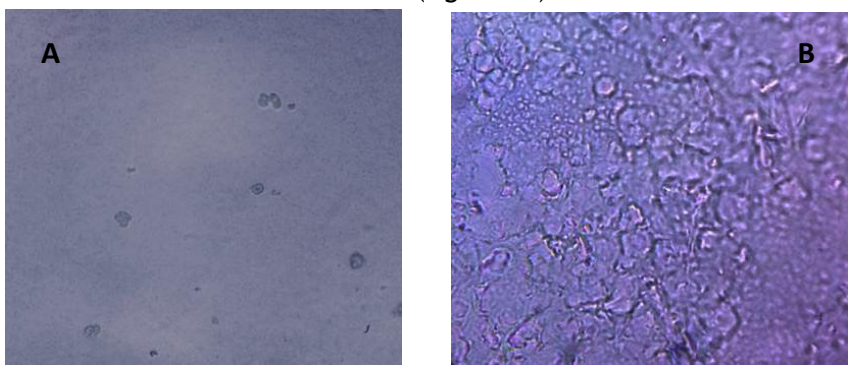

Figura 3. Micrografia de material polimérico composto de agarose e colágeno aumento x40 (A) controle material não submetido ao processo de erosão de sal. observa-se uma superfície regular sem porosidade. (B) Micrografia do material sintetizado por erosão de sal, observa-se poros de diversos tamanhos.

Leor e colaboradores (2005) observou que os polímeros naturais tiveram capacidade de conduzir o processo de adesão e proliferaçã o de cardiomiócitos. Gros e colaboradores (2010) indica a necessidade da continuidade dos estudos para de síntese de scaffolds de agarose e colágeno para reduzir as barreiras até o sucesso do desenvolvimento de novos métodos terapêuticos para o tratamento e a cura de lesões em tecidos. Também foi observado por Van Vlierberghe e colaboradores (2011) que os scaffolds de agarose e colágeno podem ser utilizados na regeneração de tecidos do pâncreas e de cartilagens. Ulrich e colaboradores (2010) demostrou em seus estudos que além da utilização no reparo de funções em tecidos lesionados, colágeno e agarose também podem servir como base para a modelagem do comportamento de células tumorais.

\section{CONCLUSÕES}

O material produzido por meio de produção de espuma não apresentou as características necessárias para sua utilização como scaffold, já que os poros e as estruturas obtidas não foram está veis. Por outro lado, o material produzido pelo método de lixiviaçã o de sais apresentou a formação de poros estáveis que teoricamente podem favorecer a adesão e a proliferação celular. Estudos futuros com cultivo celular são necessários para demonstrar a eficácia do material como scaffold.

\section{REFERÊNCIAS}

AWAD, H. A.; WICKHAM, M. Q.; LEDDY, H. A.; GIMBLE, J. M.; GUILAK, F. "Chondrogenic differentiation of adipose-derived adult stem cells in agarose, alginate, and gelatin scaffolds", Biomaterials, vol. 25, pp. 3211-3222, 2004.

BARBANTI, S. H.; ZAVAGLIA C. A. C.; DUEK, E. A. R. "Polímeros reabsorvíveis na engenharia de tecidos", Polímeros: Ciência e Tecnologia, vol. 15, $\mathrm{n}^{\circ}$ 1, p. 13-21, 2005.

BHAT, S.; TRIPATHI, A.; KUMAR, A. "Supermacroprous chitosanagarose-gelatin cryogels: In vitro characterization and in vivo assessment for cartilage tissue engineering", Journal of the Royal Society Interface, vol. 8, no. 57, pp. 540-554, 2011.

CEN, L.; LIU, W.; CUI, L.; ZHANG, W.; CAO, Y. "Collagen tissue engineering: development of novel biomaterials and applications", Pedriatic Research, vol. 63, no. 5, pp. 492-496, 2008.

DANG, J. M.; LEONG, K. W. "Natural polymers for gene delivery and tissue engineering", Advanced Drugs Delivery Reviews, vol. 58, pp. 487-499, 2006. 
GROS, T.; SAKAMOTO, J. S.; BLESCH, A.; HAVTON, L. A.; TUSZYNSKI, M. H. "Regeneration of long-tract axons through sites of spinal cord injury using templated agarose scaffolds", Biomaterials, vol. 31, pp. 6719-6729, 2010.

HUTMACHER, D. W., "Scaffolds in tissue engineering bone and cartilage", Biomaterials, vol. 21, pp. 2529-2543, 2000.

LEOR, J.; AMSALEM, Y.; COHEN, S. "Cells, scaffolds, and molecules for myocardial tissue engineering”, Pharmacology \& Therapeutics, vol. 105, pp. 151-163, 2005.

MA, P. X. "Biomimetic material for tissue engineering", Advanced Drugs Delivery Reviews, vol. 60, pp. 184-198, 2007.

MALAFAYA, P. B.; SILVA, A. G.; REIS, R. L. "Natural-origin polymers as carriers and scaffolds for biomolecules and cell delivery in tissue engineering applications", Advanced Drugs Delivery Reviews, vol. 59, pp. 207-233, 2007.

MCGEER, P. L.; MC GEER, E. "Inflammation and the degenerative diseases of aging", Annals New York Academy of Sciences, vol. 35, pp. 104-116, 2004.

SAKAI, S.; HASHIMOTO, I.; KAWAKAMI K. "Synthesis of an agarosegelatin onjugate for use as a tissue engineering scaffold", Journal Of Bioscience And Bioengineering, vol. 103, no. 1, pp. 22-26, 2007.

SANCHEZ-SALCEDO, S.; NIETO, A.; VALLET-REGÍ, M. “ Hydroxyapatite/beta-tricalcium phosphate/agarose porous scaffolds for bone tissue engineering", Chemical Engineering Journal, vol. 137, pp. 62-71, 2008.

SANTOS, R. R.; SOARES, M. B. P.; CARVALHO, A. C. C. "Transplante de células da medula óssea no tratamento da cardiopatia chagásica crônica", Revista da Sociedade Brasileira de Medicina Tropical, vol. 37, no. 6, pp. 490-495, 2004.

SITTINGER, M.; BUJIA, J.; ROTTERT, N.; REITZELT, D.; MINUTHF, W. W.; BURMESTE, G. R. "Tissue engineering and autologous transplant formation: practical approaches with resorbable biomaterials and new cell culture techniques", Biomaterials, VOL. 17, pp. 237-242, 1996.

ULRICH, T. A.; JAIN, A.; TANNER, K.; MACKAY, J. L.; KUMAR, S. “ Probing cellular mechanobiology in three-dimensional culture with collagen-agarose matrices”, Biomaterials, vol. 31, pp. 1875-1884, 2010.

VAN VLIERBERGHE, S.; DUBRUEL, P.; SCHACHT, E. "Biopolymerbased hydrogels as scaffolds for tissue engineering applications: a review", Biomacromolecules, vol. 12, pp. 1387-1408, 2011

WHO, World Health Organization, "World health statistics 2014", ed. 10, Italy, WHO Graphics, 2014.

YANG, J. WEBB, A. R.; AMEER, G. A. "Novel citric acid-based biodegradable elastomers for tissue engineering", Advanced Materials, vol. 16, no. 6, pp. 511-516, 2004. 